\title{
Clinical and nutritional significance of intestinal bacterial overgrowth
}

\author{
FRANCIS O'GRADY AND ANGELA VINCE \\ From the Department of Bacteriology, St Bartholomew's Hospital, London
}

Symbiosis, in which two very different creatures live together in constant and largely harmonious relationship, is always interesting - not least when it concerns our own insides or outsides. The microflora of our two surfaces exposed to the elements-skin and gut - have received over the years a good deal of attention. Each probe by microbiologists has quickly revealed situations bristling with giant problems of classification of multiple species, themselves apparently held together by interdependencies and feedback controls which have proved peculiarly intractable to elucidation. Not surprisingly, the steam has tended to run out of these investigations and beyond the readily ascertainable facts that the microflora of the skin and gut are different from one another, complex in their make-up, broadly similar at the same site in different individuals, and normally maintained within extraordinarily fine limits, we know very little about the details.

But while the professional microbiologists (with rare exceptions) have been wringing their hands, clinicians have become convinced that disturbances of the bowel flora underly some of their patients' disorders, and as befits men of action, have set out to discover why. As might be expected, a minimum of study has shown that pathological states do little to alleviate the complexity which exists normally. Nevertheless a number of conditions have been shown to improve on antibacterial therapy-a finding not unreasonably interpreted as indicating bacterial participation-and changes in the bowel flora have been shown to accompany some disorders of nutrition.

\section{Potential Gut-bacteria Interactions}

Inhabitant organisms might affect the gut in various ways which are indicated in Figure 1 . They might affect the absorptive or secretory functions or the motility of the gut. They might adsorb or metabolize substances in the luminal contents. The products of such metabolism might exert local effects on the gut $\stackrel{\omega}{\omega}$ or be absorbed into the circulation. Any of these or effects might be beneficial or harmful. For example,

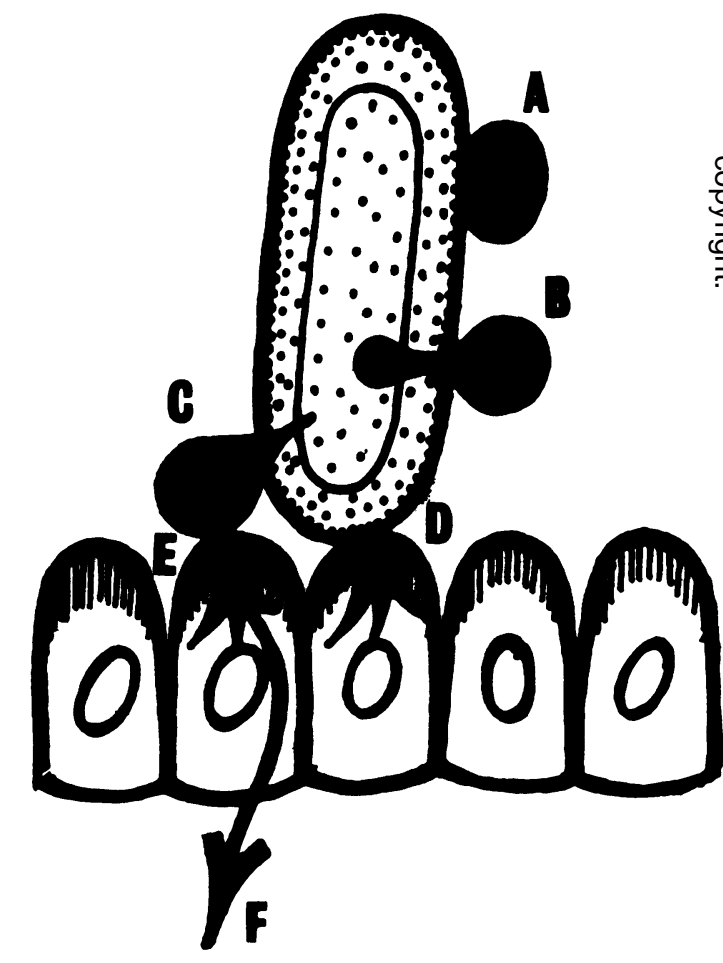

Fig. 1 Possible interactions of bacteria and gut. Bacteria may (A) adsorb or (B) absorb and metabolise gut constituents liberating products $(C)$. Gut cells may be affected by the organisms themselves $(D)$ or their products $(E)$, which may be absorbed $(F)$ into the circulation. 
bacteria might adsorb or destroy harmful substances ingested with food or manufactured in the gut, or break down ingested substances into utilizable compounds. Some bacteria exert such an effect on cellulose (Hungate, 1966) which man cannot metabolize. Bacteria might manufacture for their own purposes compounds which, through over-exuberant production or on disintegration of the bacteria, the host could utilize. Bacteria are known, for example, to synthesize a number of vitamins and in special circumstances circulating folate has been shown to be in part of bacterial origin (Hoff brand, Tabaqchali, and Mollin, 1966).

\section{DETRIMENTAL EFFECTS}

Conversely, bacteria might adsorb or destroy compounds valuable - or even essential — to the host, liberate products which locally depress gut function, or exert remote toxic effects. The first of these disagreeable possibilities: the binding or splitting of valuable gut constituents has received a fair amount of attention. Some bacteria are able to bind vitamin $B_{12}$ (Booth and Heath, 1963) so depriving the host of his dietary supply with resulting anaemia and sometimes neurological sequelae. Some gut bacteria are able to split bile salts from their natural combinations with glycine or taurine (Donaldson, 1966; Garbutt, Wilkins, Lack, and Tyor, 1970), the conjugated forms of which are required for the micelle formation which precedes fat absorption (Dawson, 1971) so inducing steatorrhoea and, through the excessive concentration of free bile salts in the gut lumen, diarrhoea. Many bacteria are able to split protein and sufficient competition by luminal bacteria for dietary protein can render the host protein deficient (Jones, Cragie, Tavill, Franglen, and Rosenoer, 1968).

In addition to these deprivations from effects on luminal contents, intoxication may result from the absorption of products of intestinal bacteria. Such 'auto-intoxication' and its management occupied a good deal of medical (and surgical) thought earlier in the century (Hale White, Andrewes, Harley, Saundby, Arbuthnot Lane, and Colyer, 1913), which was fostered by the demonstration that some characteristic products of bacterial degradation of protein (like putrescine and cadaverine) could be highly poisonous, and others (like indican) could be demonstrated in human urine. More recently, interest in enterobacterial intoxication has been revived by assorted evidence that failure of the cirrhotic or bypassed liver to detoxify compounds which are almost certainly of gut bacterial origin underlies the severe and even fatal encephalopathy which may develop in such cases (Chalmers, 1960; Zeegan, Drinkwater, Fenton, Vince, and Dawson, 1970).
METABOLIC POTENTIAL

The ability of bacteria to carry out many of these activities is well established, but for their expression in the patient, several requirements must be fulfilled. There is wide variation in the metabolic capacities of different species and even of different strains of the same species so that any effects may demand the presence in the gut (in adequate numbers) of a particular organism. Shimada, Bricknell, and Finegold (1969) have, for example, extensively examined the capacity of gut bacteria to deconjugate bile salts. They found amongst other things that all Streptococcus faecalis but no enterobacteria were capable of this metabolic trick and also (very importantly) that some strains of bacteroides were capable and some were not. Similarly, in a study of our own some years ago (O'Grady, 1967) we found that none of the Gram-positive organisms examined and only a proportion of the Gram-negative ones were capable of splitting protein to give ammonia, which is believed (but not by all) to be an important component of the intoxicating mixture liberated by bacterial proteolysis in the gut (Phear and Ruebner, 1956).

This is not the place to argue the basis of these differences, nor to discuss how much of the variation commonly found amongst bacteroides arises from difficulties in the classification of these organisms. It suffices to say that no organism possesses all metabolic capabilities, and unless one which is suitably equipped is present, a particular metabolic effect cannot be expected to occur.

Before leaving the topic of metabolic potential mention must be made of one other possible complication. Chemical transformations in and by bacteria are generally carried out in a series (sometimes long) of small steps involving small changes of energy. Situations are known to occur in which different organisms cooperate in carrying out sequential steps of such a series when one organism is incapable of one step and the other of another (Umbarger and Mueller, 1951). The gut provides rich opportunities for such collaborative enterprises, and there arises the possibility that not merely a particular organism but a particular partnership may be necessary to achieve a certain metabolic effect.

\section{Location and Growth of Bacteria in the Bowel}

Supposing a suitable organism, pair or group to be introduced into the bowel, no expression of its metabolic potential will be seen in the host unless other requirements are also fulfilled. These may be grouped under: intimacy of relation to gut cells, conditions of bacterial growth, and site of bacterial multiplication in relation to functional areas of the gut. Generally speaking, when we talk about in- 


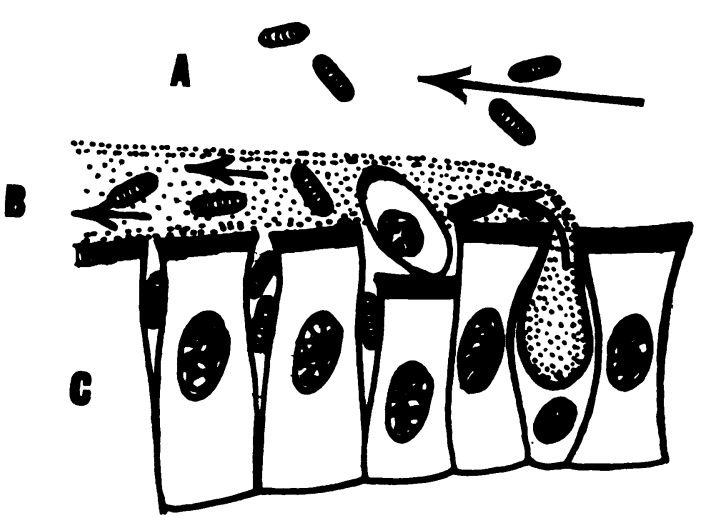

Fig. 2 Possible locations of gut bacteria. Multiplying bacteria may be in flow in the luminal fluid $(A)$, in flow in the viscid surface layer $(B)$, or 'fixed' on or between cells $(C)$.

testinal bacteria we refer to those in the gut lumen which are readily demonstrated by examination of bowel contents. It may ultimately emerge that these are much the least important in affecting the functions of the gut. Figure 2 shows three possible locations of bacteria: (1) luminal bacteria in flow in the gut contents; (2) surface bacteria in flow in mucus; and (3) 'fixed' bacteria lying between or on gut cells. We have at present no satisfactory methods for regularly sampling any but the luminal bacteria. This would be of little importance if there were good reason to believe that luminal, surface, and cellassociated bacteria closely correspond in representation of species and type. Unfortunately, the little evidence that we have on this point suggests that this is not necessarily so. Table I shows the organisms recovered from surface mucus and from homogenized mucosa obtained at the same time as luminal aspirate. The disparities seen (especially where the

\begin{tabular}{lccl}
\hline $\begin{array}{l}\text { Organisms } \\
\text { Cultured }\end{array}$ & $\begin{array}{l}\text { Luminal Fluid } \\
\text { (organisms/ml) }\end{array}$ & $\begin{array}{l}\text { Total Organisms } \\
\text { in Biopsy }\end{array}$ & $\begin{array}{l}\text { Presence in Mucus } \\
\text { of Organisms } \\
\text { Morphologically } \\
\text { Resembling those } \\
\text { Cultured }\end{array}$ \\
\hline Klebsiella & 90 & 428 & + \\
Lactobacilli & $1.4 \times 10^{4}$ & 0 & + \\
Streptococci & 0 & 0 & + \\
Micrococci & $1.7 \times 10^{2}$ & $10^{3}$ & 0 \\
Yeasts & 90 & 0 & - \\
Veillonella & $1.4 \times 10^{3}$ & 0 & \pm \\
\hline
\end{tabular}

Table I Organisms recovered from jejunal aspirate and washed homogenised biopsy or seen in mucus from biopsy surface

${ }^{1} 0=$ not recovered (or seen); $\pm=$ scanty $;+=$ present $;++=$ numerous. numbers are small) may be sampling errors. On the $\frac{\bar{J}}{0}$ other hand they may indicate real differences in species representation which, considering the dis-으 parity in growth conditions between the lumen and the wall, would not be altogether unexpected.

\section{CULTURAL CONDITIONS}

Organisms fixed on or between cells differ from those $\frac{\overline{\bar{c}}}{\overline{\frac{\sigma}{a}}}$ in conventional static cultures in that supply of fresh $\underset{\Omega}{\overparen{Q}}$ nutrient and discharge of products can occur continuously. In still greater contrast, luminal organisms ${ }^{\infty}$ and those in surface secretions multiply in flowing. systems which incorporate some aspects of con- $\overrightarrow{\vec{H}}$ tinuous cultivation. However, conditions in the gut $\stackrel{\omega}{\omega}$ include novel features which combine to produce a situation which is not encountered, and has not yet is been simulated, elsewhere.

In continuous cultivation systems, the organisms grow in a constant volume of completely mixed $\overrightarrow{.}$ nutrient to which fresh medium is added at the same rate at which the generated culture is removed. A음 bacterially populated segment of the gut resembles these conditions in that fresh nutrient is added in $c_{\mathscr{g}}$ food and gut secretions to the mixed contents which? leave the segment at a rate which approximates to that at which fresh material enters. Beyond that, the similarity ends.

Conditions differ basically in that one of the mog्e important features of successful artificial continuout o cultivation systems is the constancy of composition and addition of medium. In the gut, nutrient supply to the organisms fluctuates with food intake, digestion, and absorption. Moreover, there are important $\frac{}{\Phi}$ physical differences in the state of the culture. The $\underset{\Rightarrow}{\Rightarrow}$ constancy of the milieu in artificial systems depends as much on uniform distribution of bacteria by complete mixing as on constant composition of the medium. In the gut, material leaving a segment is not completely mixed with that entering and the con-웅 tents are subject, to a greater or lesser extent, to $\frac{-}{7}$ piston-like propulsion. Mixing at right angles to the direction of flow is facilitated by peristalsis but even $\delta$ there flow close to the walls is likely to be more $₹$ sluggish and to behave to some extent as a separate 음 system (O'Grady and Cattell, 1966; Boni, 1967).

In addition, as the terminal part of the bowel is approached the contents undergo the extraordinary process (for a bacterial culture) of progressive solidi- o fication which alters the medium composition, $\mathbb{O}$ further reduces mixing, and fixes the organisms in spatial relationship with one another. Conditions in the surface mucus must resemble somewhat those which exist in the more viscid terminal bowel con- $\frac{\bar{D}}{\Phi}$ tents, but an element of continuous cultivation is still $\stackrel{\infty}{+}$ contributed by the regular addition of fresh medium to a multiplying bacterial culture which is in flow. 
Stability of the microbial ecosystem

The particular importance of a continuous cultivation element to gut conditions is two-fold. First, such cultures, when fully established, are highly resistant to the intrusion of foreign organisms. However, by introducing several species at an early stage to the unestablished culture it is possible to produce continuous cultures in which a number of different species coexist in a stable relationship just as they do in the bowel (Collard and Gossling, 1969).

It appears that in a complex ecosystem of this kind the species are highly interdependent, some providing by their metabolism the local conditions, for example low $p \mathrm{H}$ or $\mathrm{Eh}$, required by others. Boni (1967) points out that such interdependence, in which the behaviour of each species is to some extent fixed by the behaviour of others, confers on the complex as a whole a stability which may be much greater than that shown by any of the constituent species growing alone.

\section{Perfusion/volume ratio}

Besides this intrinsic stability, there is a second reason why the element of continuous cultivation is important to conditions of growth in the bowel. In a fixed volume culture, which is being continuously supplied with fresh medium, a steady output of bacteria will be maintained only as long as growth can keep pace with the rate of dilution and displacement. Since there is a limit to the rate at which bacteria can divide there is a limit to the rate at which fresh medium can be added if the growing bacteria are not simply to be swept away. If this critical perfusion/volume ratio (O'Grady and Cattell, 1966) is exceeded, then the growing bacteria, despite multiplying at the maximum possible rate, will be progressively diluted until the perfused volume ultimately becomes sterile.

\section{CONDITIONS IN THE BOWEL}

In the bowel, the intrinsic stability of multispecies continuous cultivation systems and their precise dependence on constancy of the milieu and the perfusion/volume ratio has to be seen in a much more complex setting. Changing nutrient supplies, incomplete mixing (exacerbated by disorders of the bowel), and progressive segmentation of the culture as it progresses through the gut may provide opportunities for the introduction of freshly added organisms which do not exist in artificial cultures. Moreover the gut culture suffers the most unusual fate of regular bombardment by fresh organisms. Some of these are microbial inhabitants (normal or abnormal) of the mouth and adjacent structures, and some are put into the mouth on carriers which, like fingers, are removed, or, like food, swallowed. The fate of these organisms is summarized in Figure 3. Swallowed organisms are subjected to sequential dilution, nutrition, and possible attack by specific and non-specific inhibitors in stomach, duodenal, and intestinal juices. At the same time they find themselves propelled along in an environment from which nutrients suitable for their growth and (later

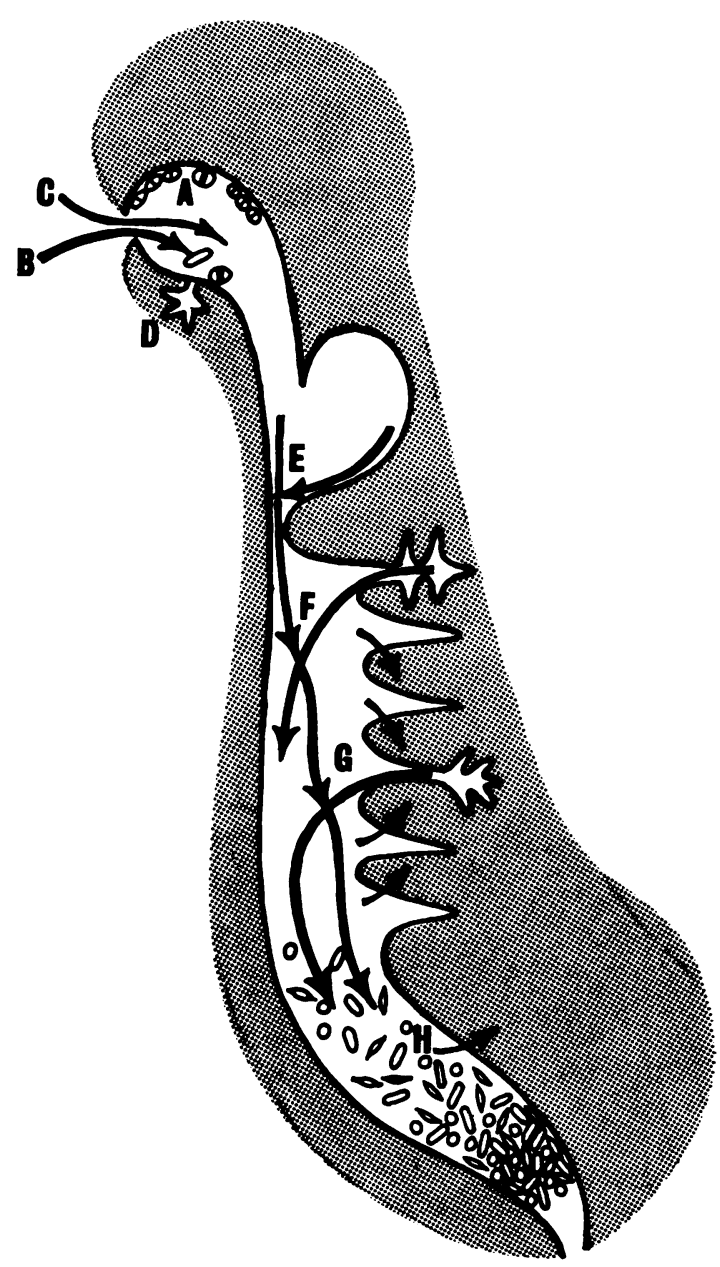

Fig. 3 Complex dynamics of the gut flora. Organisms lining $(A)$ or introduced $(B)$ with materials $(C)$ into the mouth are regularly swallowed with saliva $(D)$. Their environment is augmented and altered by secretions of the stomach $(E)$, duodenum $(F)$, and intestine $(G)$ where nutrients are removed and flow is too rapid for a stable population to develop. In the lower gut a stable ecosystem forms which is progressively dehydrated $(H)$. 
the water of their environment) progressively disappear as absorption proceeds.

SITES OF BACTERIAL GROWTH IN RELATION TO FUNCTIONAL AREAS OF THE BOWEL

Even if these organisms were fortunate enough to find nutrients in the upper gut which optimally suited their growth, the rate of dilution and propulsion is such there (Dillard, Eastman, and Fordtran, 1965) that a stable flora could not be established. The result is that characteristic members of the mouth flora like neisseria show simple progressive dilution in numbers along the length of the gut, while escherichia appear in increasing numbers although it is not until the terminal ileum is approached that conditions conducive to the establishment of a stable culture are found (O'Grady, Dawson, Dyer, Hamilton, and Vince, 1971). In this connexion, the behaviour of bacteroides (Fig. 4) is particularly instructive since stable populations are found both in the mouth and in the terminal bowel; but in the upper gut, where the perfusion/volume ratio exceeds the critical value, bacteroides are found only in transit and in relatively small numbers.

The outstanding importance of this is that in those parts of the gut principally concerned with absorption the perfusion/volume ratio is normally

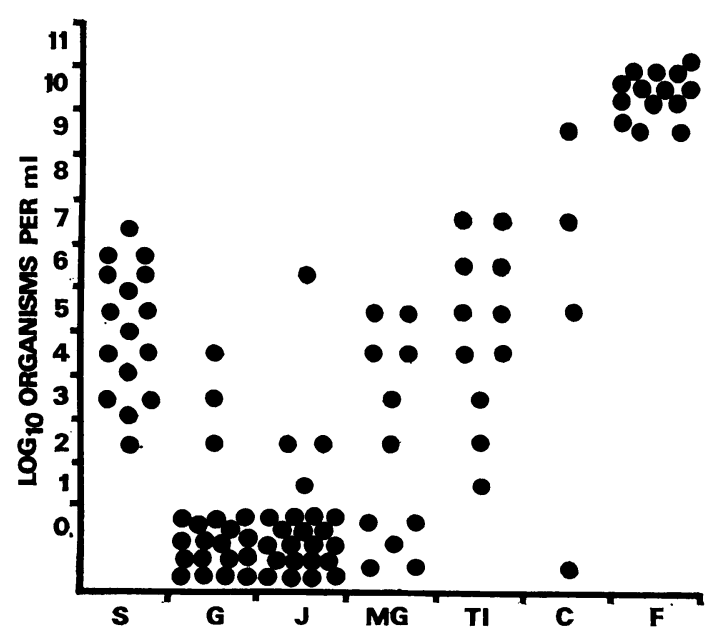

Fig. 4 Concentrations of bacteroides per $\mathrm{ml}$ in $(S)$ saliva, $(G)$ gastric juice, $(J)$ jejunal, $(M G)$ mid-gut, (TI) terminal ileum, $(C)$ colonic contents, and $(F)$ faeces. Infrequency of recovery and low counts in jejunum (exception probably due to sample containing much saliva), where perfusion/volume ratio is high and organisms are in transit, contrasts with frequency of recovery and high counts of established populations in saliva and faeces. such that a resident population cannot be sustained. 0 It is therefore possible for organisms possessed of $\frac{0}{5}$ desirable (or undesirable) metabolic capabilities to $\underline{\text { 음 }}$ pass through the bowel without any demonstrable effect on the host. In the upper gut where they might $\stackrel{\vec{F}}{+}$ bring about clinically important changes they are swept along without establishing themselves. In the lower bowel they are out of range of the nutritional $\frac{\bar{\rho}}{\vec{\sigma}}$ functions they might affect. The importance of loca- $\stackrel{\mathbb{Q}}{\varrho}$ tion in determining the effect of gut bacteria is seen in another way in hepatic encephalopathy where $\vec{A}$

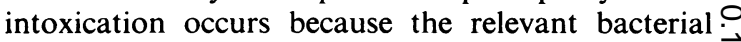
products can be absorbed from the large bowel and $\vec{\omega}$ normal freedom from their effects depends on external detoxification.

The natural separation of the principal areas of $\mathscr{\omega}$ gut function from those of bacterial establishment or means that the most important single factor leading to bacteria-based nutritional disturbances is de- $\vec{\omega}$ ranged perfusion of the upper gut. The ingestion of

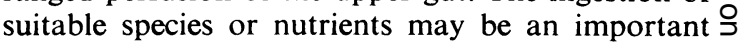
factor but will not establish bacteria in the proximal $\overrightarrow{ }$ absorptive zones of the gut unless the rates of dilution and propulsion there are reduced below the critical level. If this condition is fulfilled, bacterial colonization of the affected segment will inevitably follow. It will then become necessary to apportiog responsibility for any resulting nutritional di turbance between the bowel condition which caus the decline in perfusion and the coincident bacterial colonization. Further confusion may arise if the nutritional defect is partly offset by the fact that propulsion of the contents sufficiently sluggish to allow colonization of the upper gut also provides more time for the absorption of nutrients.

\section{Gut disease and nutritional defects}

Colonization of the upper gut will result from abnormalities of the gut wall which impair mixing and propulsion of contents or from obstruction to flow. Examples are provided by scleroderma (Salen, Goldstein, and Witts, 1966), 'blind loops' (Donaldson, 1965), gut diverticula, and stricture formation such as occurs in Crohn's disease. The role of $\subseteq$ diverticula in the maintenance of bacterial populations in otherwise adequately perfused areas is discussed by O'Grady and Cattell (1966). In all these $N$ conditions, as expected, multispecies colonization of the affected gut occurs and good examples of $\mathcal{N}$

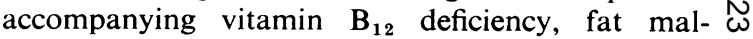
absorption, increased protein utilization, and excretion of bacterial products have been described $\varrho$ (Tabaqchali and Booth, 1967).

However, the precise make-up of the upper gut $\stackrel{\mathscr{S}}{\rightarrow}$ bacterial population resulting from bowel dys- $T$ function may differ considerably in composition and 
complexity from patient to patient depending on the nature of the defect in perfusion and mixing, and on the availability of suitably interdependent species and nutrients. Once the stable 'climax' state of the bacterial ecosystem is reached, it will be likely to resist the introduction of further organisms unless perhaps these can be slotted in as substitutes for already established members. It follows that metabolic derangement may or may not be seen depending on the nature and capabilities of the established flora, that interference with vitamin $\mathbf{B}_{12}$ absorption may be found in the absence of malabsorption of fat (and vice versa), and that excretion of bacterial products such as indican may not always accompany bacterial overgrowth in the upper gut or always be associated with malabsorption. This has certainly been our own experience with a variety of intestinal diseases in which dissociation between vitamin $B_{12}$ and fat malabsorption was encountered and we were unable to show any regular association between nutritional defects and bacterial overgrowth in the upper gut (Hamilton, Dyer, Dawson, O'Grady, Vince, Fenton, and Mollin, 1970).

Our experience has been similar in a recent more extensive study of Crohn's disease, although we readily admit that while this condition provides admirable opportunities to study bacterial colonization of the upper gut, the situation can seldom be accused of being a simple one. In addition to stricture formation, which permits bacterial colonization, some patients have entero-enteric or even enterocolic fistulae which permit the transfer of large numbers of bacteria to segments of the gut where adequate perfusion would not otherwise allow colonization.

There is in such patients the further difficulty that disease of the gut responsible for bacterial over- growth may itself be sufficient to impair absorption. As Table II shows, it was concluded that in the patients with Crohn's disease malabsorption could be accounted for by the bowel disease, though this is not to say that it was not aggravated by the presence of suitably competent bacteria.

\section{Effect of antibiotics}

In theory at least, the relative contributions of primary bowel disorder and associated bacterial overgrowth to nutritional defects should be separable by antibacterial therapy. If the nutritional abnormality is wholly or largely due to bacteria it should resolve (though not necessarily immediately) on eradication of the bacteria. Numerous impressive illustrations of such responses in individual patients have been given, including those of Tabaqchali and Booth (1967), Donaldson (1968), and Garbutt et al (1970). Similarly it is possible to show changes in the clinical state of patients with hepatic encephalopathy during periods of antibacterial therapy. Figure 5 shows the rise of blood ammonia in one of our patients with hepatic encephalopathy following the cessation of one course of neomycin therapy and its fall coincident with the administration of another.

Unfortunately much of the evidence is, like this, anecdotal, and success is often attributed to 'antibiotic' or sometimes more generously 'antibiotics' as though the properties of any one agent were very much like those of any other. Little consideration has generally been given to differences in the degree to which oral agents are absorbed, to differences in their antibacterial spectra, or to the influence of species or strains resistant to the agent. Very few reports are accompanied by any evidence that alleviation of the clinical state was paralleled by corresponding modification in the upper intestinal cultures

Number of Patients with:

\begin{tabular}{|c|c|c|c|c|c|c|c|}
\hline \multicolumn{3}{|c|}{ Excretion of Vitamin $B_{12}$} & \multicolumn{3}{|c|}{ Faecal Fat } & \multicolumn{2}{|c|}{ Urinary Indican } \\
\hline \multirow[t]{2}{*}{ Normal $^{1}$} & \multicolumn{2}{|c|}{ Decreased, with Ileum } & \multirow[t]{2}{*}{ Normal } & \multicolumn{2}{|c|}{$\begin{array}{l}\text { Increased, with Jejunum } \\
\text { and Ileum }\end{array}$} & \multirow[t]{2}{*}{ Normal $^{\mathrm{s}}$} & \multirow[t]{2}{*}{ Increased } \\
\hline & Normal $^{2}$ & Diseased $^{3}$ & & Normal ${ }^{2}$ & Diseased $^{3}$ & & \\
\hline
\end{tabular}

Bacterial overgrowth in

No bacterial overgrowth in

small gut

3

2

0

$0 \quad 5$

0

3

Table II Correlation between bacterial overgrowth in small gut, urinary indican, and metabolic defects

${ }^{1}$ More than $12 \%$ of dose in 24 hours

In absorptive area

3 Or resected

'Less than $6 \mathrm{~g} / \mathrm{day}$

Less than $100 \mathrm{mg}$ in $24 \mathrm{hr}$

- Enterobacteria, enterococci, bacteroides, or clostridia/ml jejunal or upper ileal fluid exceeds highest count in normals by at least 1 decade. 


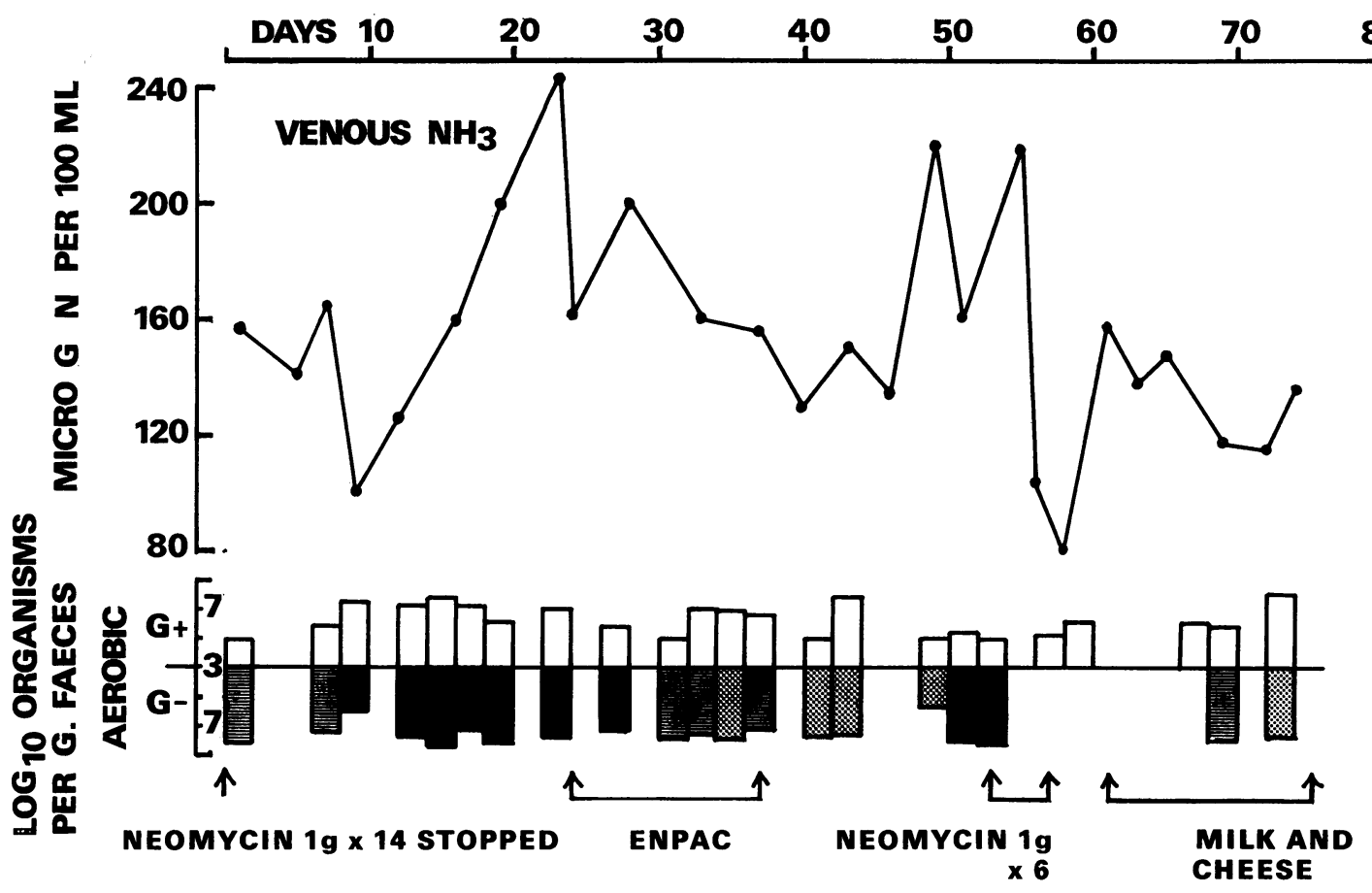

Fig. 5 Rise of venous ammonia in a patient with hepatic encephalopathy after stopping a course of neomycin therapy and its subsequent fall on reinstituting treatment. The degree of ammonia production from protein in vitro by organisms isolated from faeces is indicated by the intensity of shading. Ammonia peaks correspond with the presence of the most active ammonia-producing organisms.

Equally unfortunately, many of the observed effects have been obtained with tetracyclines or neomycins which are known to exert direct effects on cells of the host quite apart from their effects on bacteria. Tetracycline depresses the protein metabolism of mammalian cells (Edwards, Huskisson, and Taylor, 1970), and neomycin, at least in large doses, can itself induce malabsorption (Dobbins, Herrero, and Mansbach, 1968).

Nevertheless the remarkable responses to antibacterial therapy sometimes obtained, together with other evidence from quantitative studies of the upper gut flora, provide us with reasons for believing that man's intestinal microflora may influence his state of health sometimes to his benefit, more often (or at least more often recognized) to his detriment. The abundant analytical difficulty of disentangling the activities of one ecosystem inside another (the gut bacterial community in man in his community) is obvious enough, but we already have the tools to take advantage of the start which has been made. Coupled studies of bowel function (including vitally important transit times), together with quantitative bacteriology and examination of the response to $\overrightarrow{\vec{P}}$ antibacterial agents possessing defined activity against species demonstrated to be present, should $\rightleftharpoons$ soon finally establish how important to the health of: the patient is extension of bacterial colonization to the upper gut.

We are indebted to our colleagues Drs A. M. Dawson, J. C. B. Fenton, J. D. Hamilton, N. H. Dyer, and R. Zeegan for their part in the investiga- -5 tion and discussion of these patients and problems, $\frac{7}{O}$ and to the Board of Governors and Joint Research Board of St Bartholomew's Hospital for a grant $\widetilde{\sigma}$ towards the cost of this work.

\section{References}

Boni, P. (1967) Growth dynamics of the intestinal flora considered as a continuous-flow culture: A thermodynamic and hydro- $\mathbb{D}$ dynamic qualitative approach. Riv. Ist. sieroter. ital., 42, 261-288.

Booth, C. C., and Heath, J. (1963). The effect of E. coli on the absorption of vitamin $\mathrm{B}_{12}$. Gut, 3, 70-72. 
Chalmers, T. D. (1960). Pathogenesis and treatment of hepatic failure. New Engl. J. Med., 263, 23-30 and 77-82.

Collard, P., and Gossling, J. (1969). Continuous flow culture of mixtures of faecal organisms. J. gen. Microbiol., 55, 20.

Dawson, A. M. (1971). The absorption of fat. J. clin. Path, 24, Suppl. (Roy. Coll. Path.), 5, 77-84.

Dillard, R. L., Eastman, H., and Fordtran, J. S. (1965). Volume-flow relationship during the transport of fluid through the human small intestine. Gastroenterology, 49, 58-66.

Dobbins, W. O. III, Herrero, B. A., and Mansbach, C. M. (1968). Morphological alterations associated with neomycin-induced malabsorption. Amer. J. med. Sci., 255, 63-77.

Donaldson, R. M., Jr. (1965). Studies on the pathogenesis of steatorrhea in the blind loop syndrome. $J$ clin. Invest. 44, 1815-1825.

Donaldson, R. M., Jr. (1966). Intestinal bacteria and malabsorption. Ann. intern. Med., 64, 948-952.

Donaldson, R. M., Jr. (1968). Alimentary canal. In Handbook of Physiology, sect. 6, vol. 5, p. 2807, edited by C. F. Code. Williams and Wilkins, Baltimore.

Edwards, O. M., Huskisson, E. C., and Taylor, R. T. (1970). Azotaemia aggravated by tetracycline. Brit. med. J., 1, 26-27.

Garbutt, J. T., Wilkins, R. M., Lack, L., and Tyor, M. P. (1970). Bacterial modification of taurocholate during enterohepatic recirculation in normal man and patients with small intestinal disease. Gastroenterology, 59, 553-566.

Hale White, W., Andrewes, F. W., Harley, V., Saundby, R., Arbuthnot Lane, W., and Colyer, J. F. (1913). Alimentary toxaemia: Its sources, consequences and treatment. Proc. roy. Soc. Med., 6, $1-380$.

Hamilton, J. D., Dyer, N. H., Dawson, A. M., O'Grady, F. W., Vince, A., Fenton, J. C. B., and Mollin, D. L. (1970). Assessment and significance of bacterial overgrowth in the small bowel. Quart. J. Med., 39, 265-285.

Hoffbrand, A. V. S., Tabaqchali, S., and Mollin, D. L. (1966). High serum-folate levels in intestinal blind loop syndrome. Lancet, 1, 1339-1342.

Hungate, R. E. (1966). The Rumen and its Microbes, p. 36. New York, Academic Press.

Jones, E. A., Cragie, A., Tavill, A. S., Franglen, G., and Rosenoer, V. (1968). Protein metabolism in the intestinal stagnant loop syndrome. Gut, 9, 466-469.

O'Grady, F. (1967). Differences in ammonia production by faecal bacteria of patients with hepatic encephalopathy. Proc. roy. Soc. Med., 59, 1246.

O'Grady, F., and Cattell, W. R., (1966). Kinetics of urinary tract infection: I. Upper urinary tract. Brit. J. Urol., 38, 149-155.

O'Grady, F., Dawson, A. M., Dyer, N. H., Hamilton, J. D., and Vince, A. (1971). Patterns of disturbance of the gut microflora in gastrointestinal disease. In Proceedings of the Eighth International Congress on Nutrition, Prague, p. 438.

Phear, E. A., and Ruebner, B. (1956). In vitro production of ammonia and amines by intestinal bacteria in relation to nitrogen toxicity as factors in hepatic coma. Brit. J. exp. Path., 37, 253-262.

Salen, G., Goldstein, F., and Wirts, C. W. (1966). Malabsorption in intestinal scleroderma: Relation to bacterial flora and treatment with antibiotics. Ann. intern. Med., 64, 834-841.

Shimada, K., Bricknell, K. S., and Finegold, S. M. (1969). Deconjugation of bile acids by intestinal bacteria: Review of literature and additional studies. J. infect. Dis., 119, 273-281.

Tabaqchali, S., and Booth, C. C. (1967). Relationship of the intestinal bacterial flora to absorption. Brit. med. Bull., 23, 285-290.

Umbarger, H. E., and Mueller, J. H. (1951). Isoleucine and valine metabolism of Escherichia coli: I. Growth studies on aminoacid-deficient mutants. J. biol. Chem., 189, 277-285.

Zeegan, R., Drinkwater, J. E., Fenton, J. C. B., Vince, A., and Dawson, A. M. (1970). Some observations on the effects of treatment with lactulose on patients with chronic hepatic encephalopathy. Quart. J. med., 39, 245-263. 